\title{
OIM Analysis of Microstructure and Texture of a TRIP Assisted Steel after Static and Dynamic Deformation
}

\author{
Roumen H. Petrov ${ }^{\mathrm{a}}$, Jérémie Bouquerel ${ }^{\mathrm{b}}, \mathrm{Kim}$ Verbeken, ${ }^{\mathrm{c}}$ Leo A.I. Kestens ${ }^{\mathrm{d}}$, \\ Patricia Verleysen ${ }^{\mathrm{e}}$ and Yvan Houbaert ${ }^{\mathrm{f}}$
}

Ghent University, Department of Materials Science and Engineering, Technologiepark 903, B-9052 Ghent, Belgium

Roumen.Petrov@ugent.be, ${ }^{\text {a }}$ Jeremie.Bouquerel@ugent.be, ${ }^{b}$ Kim.Verbeken@ugent.be, ${ }^{c}$ Leo.Kestens@ugent.be, ${ }^{d}$ Patricia.Verleysen@ugent.be ${ }^{\mathrm{e}}$,- Yvan.Houbaert@ugent.be $^{\mathrm{f}}$

Keywords: TRIP steels, EBSD, microstructure, texture, strain, fracture.

\begin{abstract}
TRIP-assisted steel with a composition of $0.2 \% \mathrm{C}, 1.6 \% \mathrm{Mn}, 1.5 \% \mathrm{Al}$ was studied in the undeformed state, after the application of 10 and $30 \%$ static tensile strain parallel to rolling the direction of the sheet and after dynamic (Hopkinson) fracture test. Detailed examination of the microstructure and microtexture by means of electron backscattered diffraction (EBSD) was carried out in order to quantify the microstructural constituents and to study the strain distribution. The microtexture evolution and the distribution of the specific texture components between the BCC and FCC phases were studied as a function of the external strain and the strain mode-static or dynamic. The strain localization and strain distribution between the structural constituents were quantified based on local misorientation maps. The full constraint Taylor model was used to predict the texture changes in the material and the results were compared to the experimental findings.

Comparing the local misorientation data it was found that at low strains the ferrite accommodates approximately 10 times more deformation than the retained austenite. The strain localizes initially on the BCC-FCC phase boundaries and is then spread in the BCC constituents (ferrite and bainite) creating a deformation skeleton in the BCC phase.

It was found that the observed texture changes in the measured retained austenite texture after deformation do not correspond exactly to the model prediction. The austenite texture components which were predicted by the Taylor model were not found in the measured austenite texture after deformation which means that they are first transformed to martensite, which is considered as an indication for the selective transformation of austenite under strain.
\end{abstract}

\section{Introduction}

TRIP-assisted steels are subject of extensive interest for scientists and producers because of their unique combination of mechanical properties - high strength and large homogeneous elongation. As shown in the previous works these properties result from a synergic effect that combines the characteristics of ferrite, bainite and mechanically unstable retained austenite which partially transforms to martensite under strain $[1,2,3,4]$. Therefore, in order to obtain an accurate description of the microstructure-mechanical properties relation in TRIP-assisted steels, it is very important to know how the stress and strain (static or dynamic) distribute among the different microstructural constituents and how the microstructure responds to the external load. The evolution of the strain distribution within the deformation as well as the evolution of the constituents during straining is documented in [5,6] but the effect of large deformations and the high strain rates on the microstructure of TRIP steels still remains in question.

The goal of the present work is to study the changes in the microstructure and texture of TRIPassisted steel by means of the EBSD technique and to obtain a better understanding of their deformation and transformation behaviour under static and dynamic straining. 


\section{Experimental}

The laboratory cast CMnAl TRIP steel with chemical composition $0.24 \% \mathrm{C}, 1.61 \% \mathrm{Mn}, 0.09 \% \mathrm{Si}$, $1.54 \% \mathrm{Al}$ and $\mathrm{P}$ and $\mathrm{S}<0.006 \%$ (in mass.\%) was hot rolled, cold rolled to a thickness $1.1 \mathrm{~mm}$ and subsequently heat treated ( $2 \mathrm{~min}$ intercritical annealing at $840^{\circ} \mathrm{C}$ followed by austempering at $460^{\circ} \mathrm{C}$ for $2 \mathrm{~min}$ ) to obtain the microstructure of ferrite, bainite and retained austenite. Standard size A80 tensile samples according to the European Standard EN 10002-1 specification and samples for Split Hopkinson Bar (SHB) tests with gauge length of $5 \mathrm{~mm}$, a width of $4 \mathrm{~mm}$ and the heads of 25 $\mathrm{mm} \times 15 \mathrm{~mm}$ were cut from the sheets with long axis parallel to the sheet rolling direction (RD). Tensile test samples were pre-strained in a standard tensile test to 10 and $30 \%$ engineering strain and until fracture at room temperature with a strain rate of $5.6 \times 10^{-3} \mathrm{~s}^{-1}$. SHB test were carried out at room temperature and for a strain rate of $970 \mathrm{~s}^{-1}$.

Samples with size $10 \mathrm{~mm}$ x $10 \mathrm{~mm} \times 1.1 \mathrm{~mm}$ were cut from the strips and grinded and polished to half the thickness. In this plane the microstructure, texture and the amount of the retained austenite of the strips before and after 10\%, 30\% static and $45 \%$ dynamic deformation (i.e. fracture) were studied in order to evaluate the influence of the strain rate and deformation state. The volume content of the paramagnetic retained austenite $V_{\gamma}$ was determined by means of magnetic saturation and EBSD.

The samples for EBSD examination were prepared by a combination of mechanical grinding and polishing, electropolishing and a final mechanical polishing step of $0.035 \mu \mathrm{m}$ OPU for $10 \mathrm{~min}$. EBSD data were collected by Oxford-HKL EBSD system attached to a FEI Nova 600 Nanolab Dual Beam FIB-SEM with field emission gun. The EBSD patterns were acquired at acceleration voltage of $20 \mathrm{kV}$, beam current of $2.4 \mathrm{nA}$, a specimen tilt of $70^{\circ}$ and a working distance of $7 \mathrm{~mm}$. Scan step sizes of $0.02 \mu \mathrm{m}$ and $0.05 \mu \mathrm{m}$ on a square scan grid and binned pattern size $2 \mathrm{x} 2$ were used to obtain good angular and spatial resolution of the measurement. The EBSD data were postprocessed by means of both Channel 5 (Oxford-HKL) and OIM Data Analysis 4.6 (EDAX-TSL) commercial software.

Part of the orientation data were post-processed also by means of the MTM - FHM software developed by Van Houtte [7]. The texture model based on the full constraint Taylor model [8] was used to predict the texture changes in the FCC and BCC phases and the results were compared with the experimental data. The $\{110\}\langle 111\rangle$ and $\{112\}\langle 111\rangle$ slip systems were used to simulate the deformation of the BCC phases whereas for the FCC phase the $\{111\}\langle 110\rangle$ slip systems were considered.

\section{Results and Discussion}

The microstructure of the undeformed steel is shown in Fig.1a by means of a combined grey scale image quality map and colour coded phase map. The austenite phase in this map appears in dark grey, whereas ferrite and bainite are in light grey colours. The main difficulty is to distinguish bainitic ferrite from ferrite because both have a bcc crystal structure. The most important difference between them is the occurrence of transformation induced geometrically necessary dislocations (GND) in the bainitic phase. Indeed, several experimental studies have shown that the bainite has higher dislocation densities in comparison with ferrite $\left(10^{13} \mathrm{~m}^{-2}-10^{14} \mathrm{~m}^{-2}\right.$ for bainite and $10^{12} \mathrm{~m}^{-2}-$ $10^{13} \mathrm{~m}^{-2}$ for ferrite) [10]. These differences are quantifiable and they can be measured by tracing the variations of the EBSD pattern quality (Image Quality) [6,9] or by accurate measuring of the local misorientations known as kernel average misorientation (KAM) and applying appropriate selection criteria as it was proposed by Zaefferer et al. [11]. According to this approach, for a given pixel (kernel) the average misorientation of that point with all of its neighbours was calculated with the condition that misorientations exceeding some tolerance value are excluded from the averaging calculation. It is obvious that with such an approach the value of the calculated misorientations will be dependent on the step size. To avoid this, the different neighbours may be selected (nearest, next-nearest or next-next-nearest) to define the kernel. In order to improve the sensitivity of the 
KAM value and to adapt the kernel size to a given measurement step size it can be calculated with respect to higher order neighbours. In this work always 3 neighbours and $5^{\circ}$ cut off criterion are used for calculation of KAM.
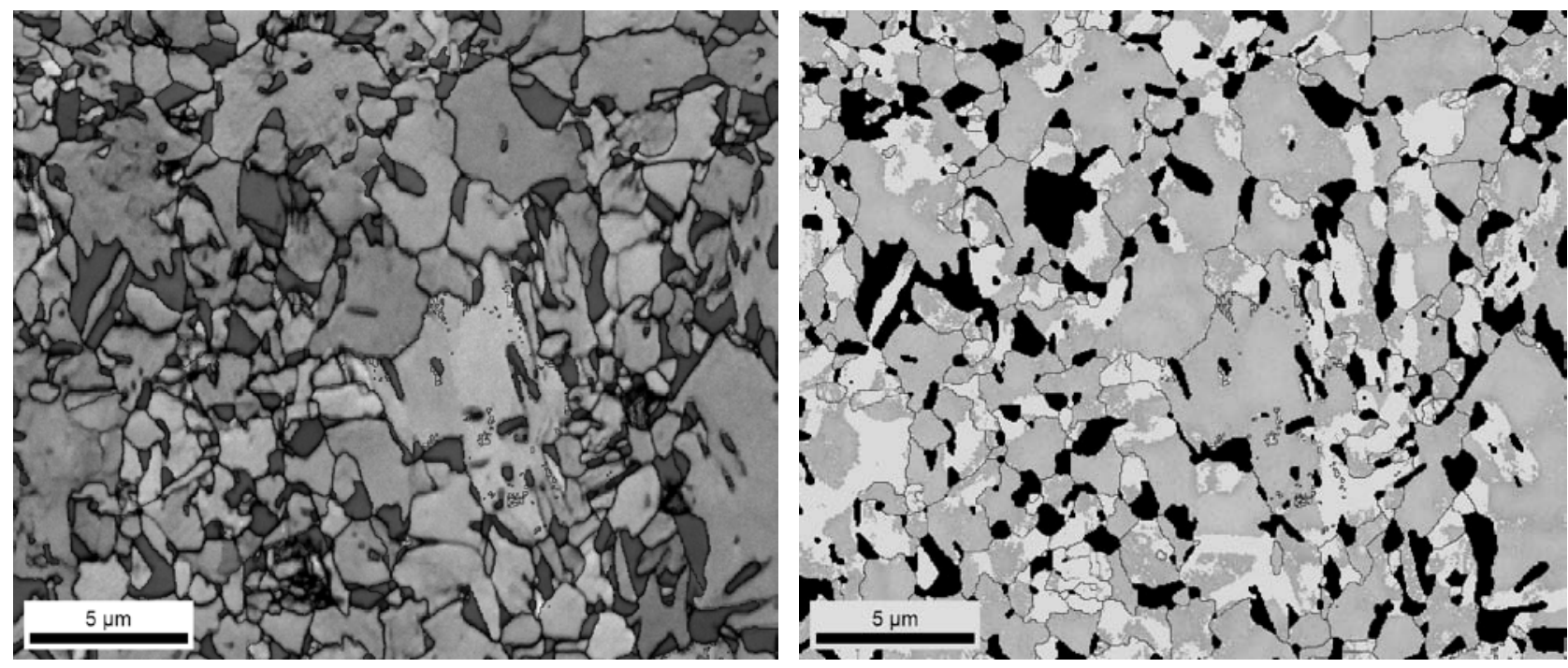

Fig. 1: (a) Combined image quality and phase map of undeformed sample; Retained austenite is dark, ferrite and bainite are in light grey; (b) The same region after post-processing the data according the procedure proposed by Zaefferer et al. [11]. The bainite is light grey, ferrite dark grey and retained austenite is black.

Applying the above mentioned approach [11] to the EBSD data the bainite zones, shown in white in Fig.1b) are successfully separated from the ferrite as a zones with KAM between $0.52^{\circ}$ and $5^{\circ}$ and the bainite fraction is quantified to be $28.6 \%$ which is in very good agreement with the data from the optical microscopy quantification after tint etching (LePera) as well as with the expectation from the heat treatment. (Table1). The fraction of retained austenite in deformed samples determined by MS is significantly larger than the one measured by OM and EBSD which could be linked to the higher sensitivity of the method to the small zones with inter-lath retained austenite which remains untransformed but are beyond the resolving power of OM and EBSD. On the other hand, the results from MS after 30\% strain should be accepted with care because the strain distribution in the examined zone is heterogeneous due to necking and the local measurements by EBSD are more reliable as far as they refer just to the zone with the highest strain.

\begin{tabular}{|l|c|c|c|}
\hline $\begin{array}{l}\text { Fraction } \\
(\%)\end{array}$ & OM & EBSD & MS \\
\hline $\begin{array}{l}\text { Retained } \\
\text { austenite }\end{array}$ & 16 & 16.8 & 16.9 \\
\hline Bainite & 31 & 28.6 & --- \\
\hline Ferrite & 51 & 54.6 & --- \\
\hline $\begin{array}{l}\text { \# of grains / } \\
\text { \# of scans }\end{array}$ & $\begin{array}{c}200 / \\
3\end{array}$ & $\begin{array}{c}20-50 / \\
2\end{array}$ & $\begin{array}{c}\text { whole } \\
\text { sample }\end{array}$ \\
\hline
\end{tabular}

Table 1. Fraction of the microstructural constituents determined with different methods optical microscopy (OM), EBSD and magnetic saturation (MS)

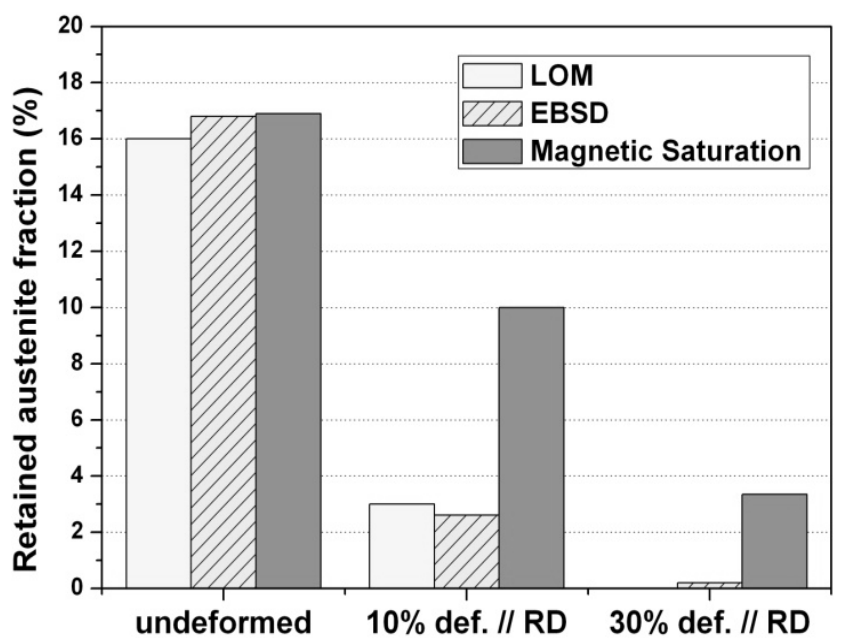

Fig.2: Fraction of retained austenite as a function of applied strain. 
The analysis of the strain distribution among the microstructure constituents was made based on the quantification of grain average orientation deviation (GROD) which links the strain level to the absolute lattice rotation [12]. The data are shown in Fig. 3a, b. Comparing the averaged values for GROD data it was found that at $10 \%$ static strain the ferrite accommodates approximately 2 times more deformation than the retained austenite and it is localized mainly around the phase boundaries. With increase of the strain up to $30 \%$ the lattice GROD of the BCC constituents increases with $800 \%$ with respect to the undeformed material, whereas the increase of GROD in the measured part of the retained austenite is only $200 \%$ in comparison with the initial state. It is interesting to mention that there were no remarkable changes in the microstructure or GROD values comparing the static and dynamic modes. Therefore one can conclude that the strain localizes initially on the BCC-FCC phase boundaries and then is spread in the BCC constituents (ferrite and bainite) creating a deformation skeleton in the BCC phase (cf. Fig. 4).

The ODF of the retained austenite in the undeformed TRIP steel contains brass $(\{110\}\langle 112\rangle)$ texture component with an intensity of $3 x$ random and Goss $(\{110\}<001\rangle)$ component with an intensity of $4 \mathrm{x}$. After $10 \%$ of plastic strain, the intensity of Goss texture components decreases to $2 \mathrm{x}$ random and after $30 \%$ strain this texture component disappears completely from the ODF whereas
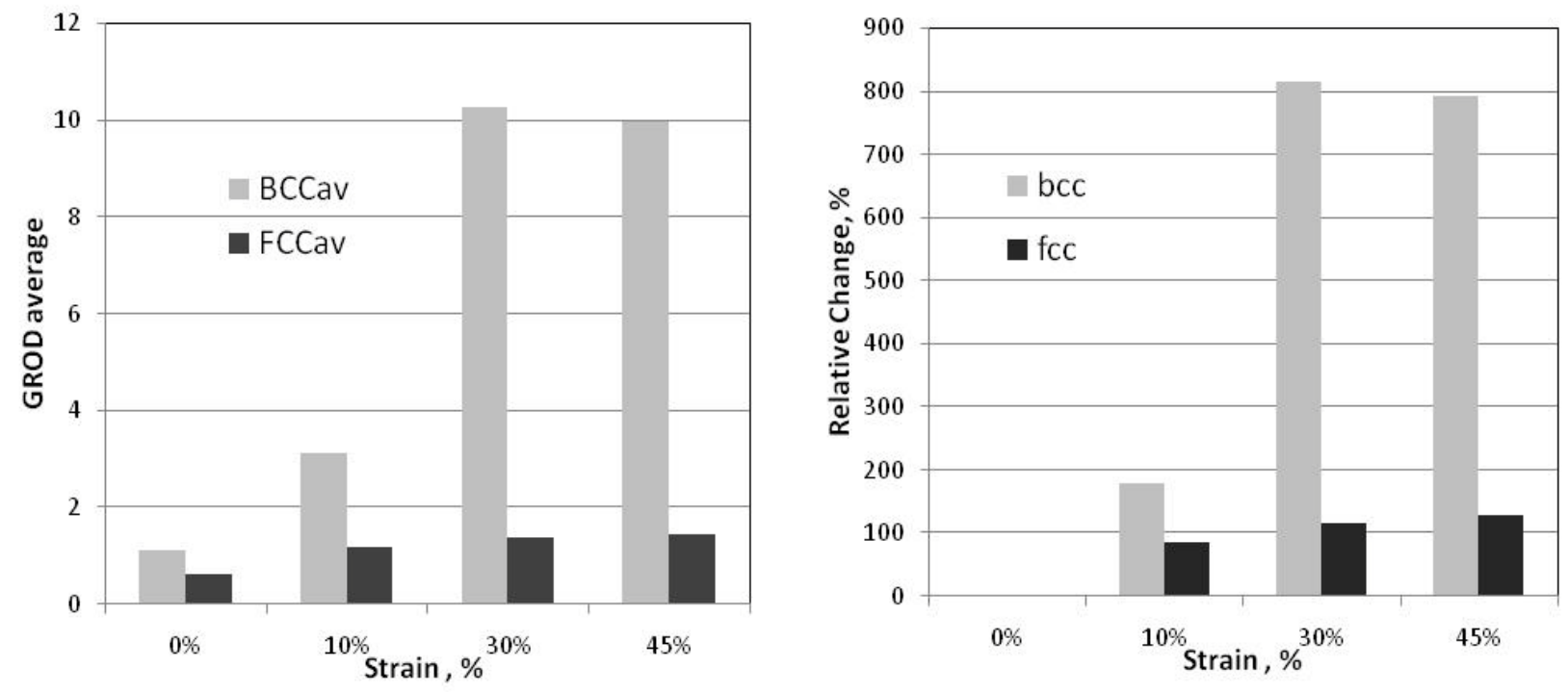

Fig.3: (a) Changes in the averaged GROD and its distribution among the retained austenite (FCC) and the BCC phases (ferrite + bainite) as a function of strain; (b) Relative changes in the GROD in the same constituents calculated as $\left(\mathrm{M}_{\text {def }}-\mathrm{M}_{\text {undef }}\right) * 100 / \mathrm{M}_{\text {undef }}$.

the brass texture component is reoriented $\sim 10^{\circ}$ about the sample's ND giving rise to the $\{110\}\langle 433\rangle$ texture component with an intensity of 12.47. (cf.Fig.5). Two possible mechanisms can be discussed to explain these observations: (i) the texture components disappear because of crystal rotations related to deformation in they -phase and (ii) these orientations are among the first that transform to martensite.

For an approximate evaluation of possible texture changes in the retained austenite texture after $10 \%$ and $30 \%$ strain the full constraint Taylor model was applied for the uniaxial strain condition. Although the Taylor model is not very accurate and the local strain mode in the retained austenite islands probably differs significantly from the uniaxial extension mode, it is expected that an approximate value for the magnitude of the texture changes can be obtained by this simulation. 


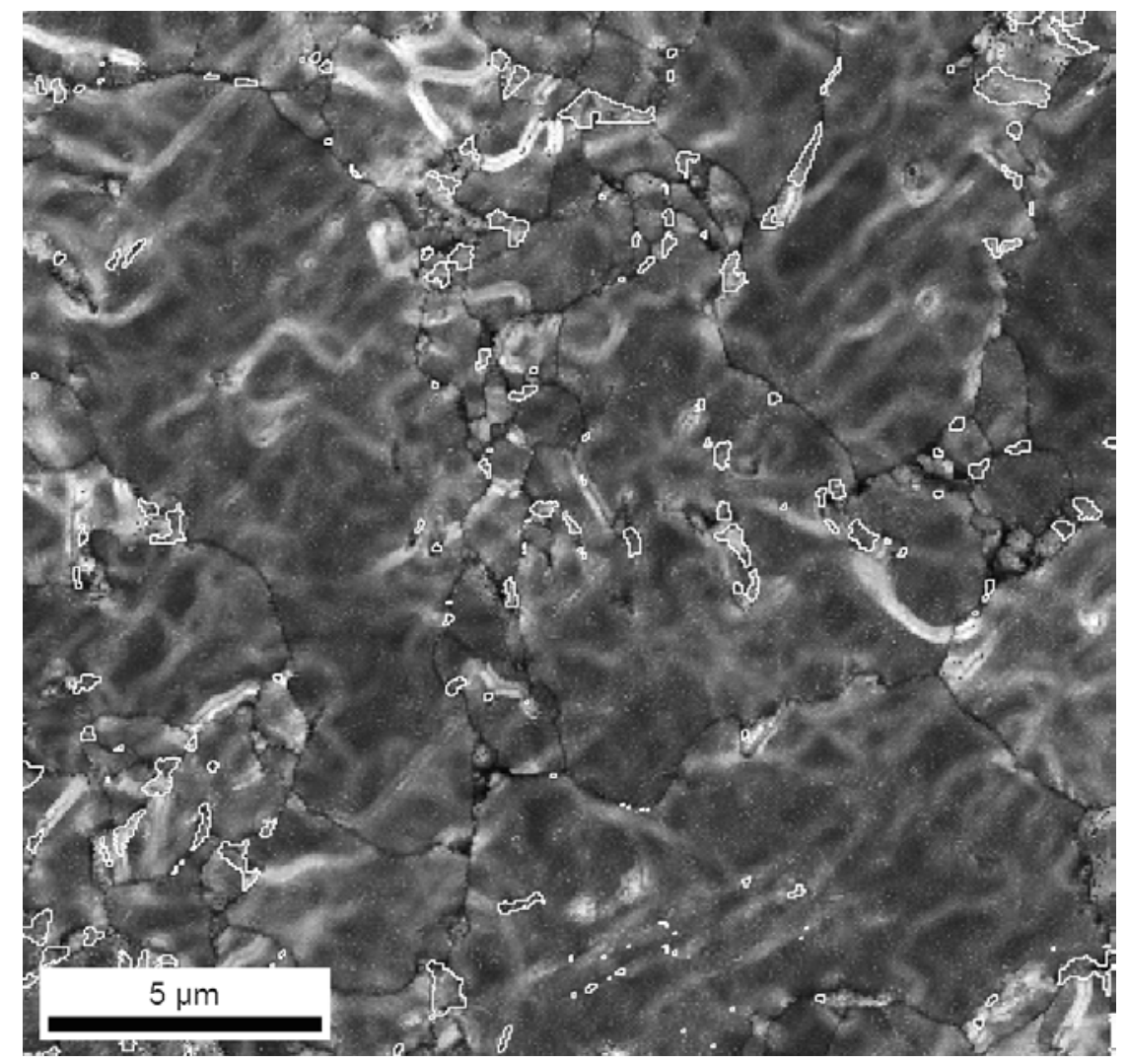

Fig.4: Gray scale KAM ( $3^{\text {rd }}$ neighbors, max $5^{\circ}$ ) map showing misorientation localization in the vicinity of the phase boundaries (white) in sample after $10 \%$ strain.

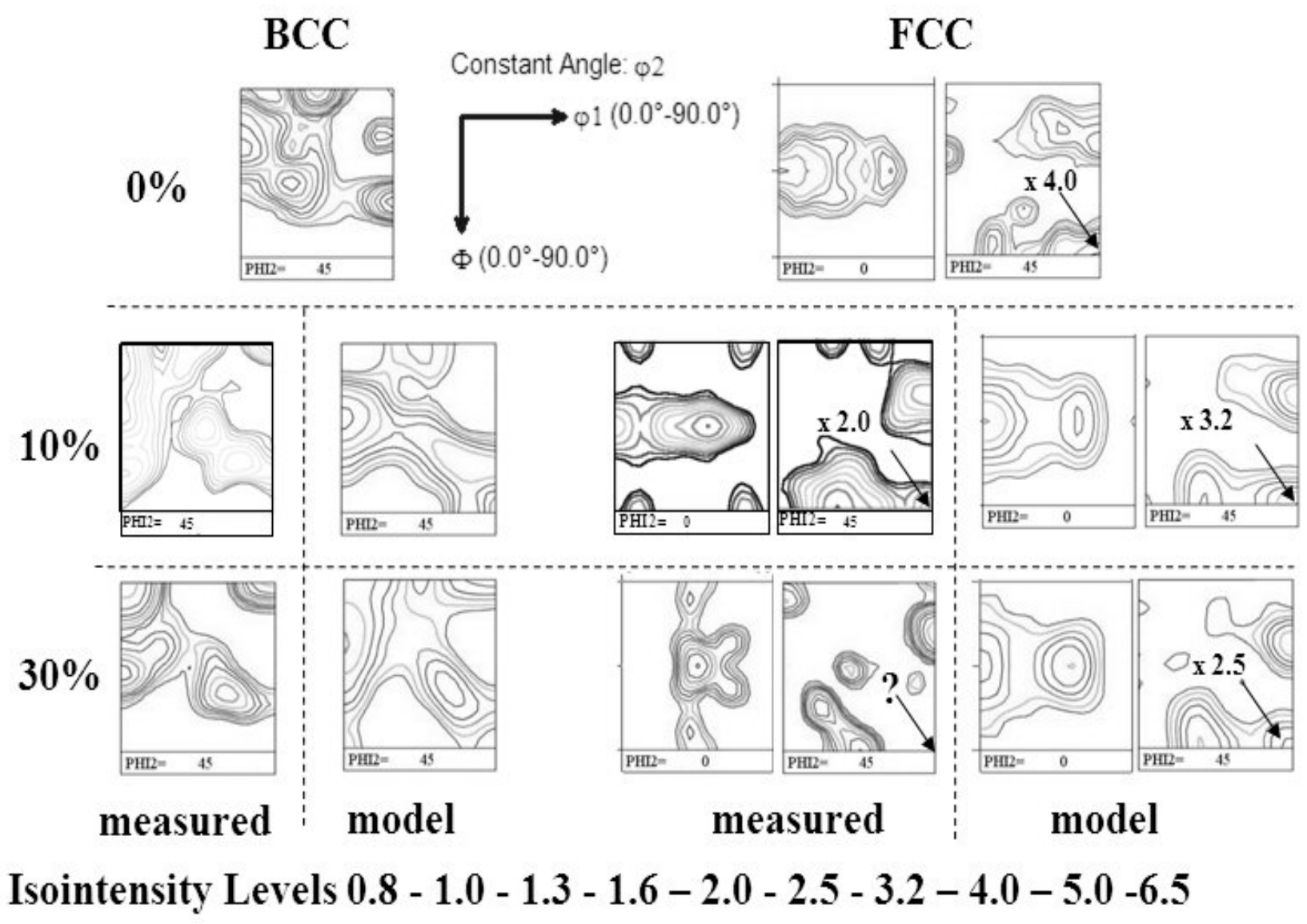

Fig.5: Texture changes in the BCC and FCC constituents as a function of applied static strain measured and modeled.

The results of the Taylor simulation (Fig.5b middle) predicted correctly the BCC texture changes 
and the rotation of the brass and the copper texture components and they display also that the Goss textures should be present in the ODF after deformation of $10 \%$ with lower intensity and also after $30 \%$ strain. The observed texture changes (i.e. the complete disappearance of the $\{110\}\langle 001\rangle$ texture component from the ODF) in the measured retained austenite texture after $30 \%$ deformation (Fig.5b, right) does not correspond exactly to the model prediction. Therefore, it is more likely to attribute the disappearance of the Goss $\{110\}\langle 001\rangle$ component to the selective transformation to martensite which is also supported by the above observation that the residual austenite grains hardly accommodate any deformation as derived from the fact that their average interior misorientation was not changed significantly after applying the 30\% tensile strain (cf. Fig.4). Hence, one can conclude that the hard austenite particles behave like a stiff inclusion in a soft ferrite matrix which accommodates the greater part of the tensile strain.

\section{Conclusions}

The microstructure and microtexture of the TRIP-assisted steel sheets were examined in detail by means of EBSD in order to quantify the microstructural constituents and to study the strain distribution. It was found that irrespectively of the strain conditions, i.e. static or dynamic, the BCC phase accumulates the main part of the deformation, whereas the retained austenite remains almost undeformed but transforms selectively to martensite. The orientation selection is manifested as preferential transformation of the retained austenite with Goss texture to martensite.

\section{Acknowledgments:}

The help of Dr. ir. Joost Van Slycken with Hopkinson tests is gratefully acknowledged. K.V. is a postdoctoral fellow with the Fund for Scientific Research-Flanders (Belgium) (F.W.O. Vlaanderen).

\section{References}

1. E. Girault: "Bainitic Transformation in TRIP-Assisted Steels and its Influence on Mechanical Properties", Ph.D. Thesis, MTM, KU Leuven, (1999).

2. P. Jacques: "On the Physics and Mechanics of Phase Transformations in TRIP-Assisted Multiphase Steels”, $\mathrm{PhD}$ thesis, UCL, (1998).

3. M. De Meyer: "Transformation and mechanical properties of cold rolled and intercritically annealed CMnAlSi TRIP-aided steels”, PhD Thesis, Dept. of Metallurgy and Materials Science, Ghent University, Belgium, (2001).

4. L. Barbé, K.Verbeken and E.Wettinck: ISIJ International, 46 (8), (2006), pp. 1249-1255

5. Q. Furnémont: "The micromechanics of TRIP-assisted multiphase steels ", $\mathrm{PhD}$ thesis, UCL, (2003).

6. R. Petrov et al., Mater. Sci. Eng. A, Vol. 447, (2007), pp. 285-297.

7. P.Van Houtte: MTM-FHM Software User Manual, MTM-KU Leuven, 1995. (private communication).

8. P.Van Houtte: Text.\& Microstructure, Vols. 8-9, (1988),pp. 313-350.

9. M. De Meyer, L. Kestens, and B. C. De Cooman: Mater. Sci. Technol., Vol. 17, (2001),pp. 1353-1359.

10. H.K.D.H. Bhadeshia: Bainite in Steels, Second edition IOM Communications Ltd, The University Press Cambridge, (2001) p.28.

11. Zaefferer, S. , Romano P. and Friedel F: Journal of Microscopy, Vol. 230, Pt 3 2008, pp. 499-508.

12. N. Zaafarani, et al., Acta Mater., Vol. 56, (2008), pp. 31-42. 